\title{
Thirty Years (and More) of Hair Research Societies
}

\author{
Gill Westgate ${ }^{a, b}$ Wilma F. Bergfeld ${ }^{a, c}$ Victoria Ceh ${ }^{a, c}$ Maria Hordinsky ${ }^{c}$ \\ Rodney Sinclair ${ }^{d}$ Bianca Maria Piraccini $^{b}$ Hoon Kang $^{e}$ Manabu Ohyama $^{f}$ \\ anternational Federation of Hair Research Societies, Chicago, IL, USA; ${ }^{b}$ European Hair Research Society, University \\ of Bologna, Bologna, Italy; 'American Hair Research Society, Chicago, IL, USA; ${ }^{\mathrm{d} A u s t r a l a s i a n ~ H a i r ~ a n d ~ W o o l ~ R e s e a r c h ~}$

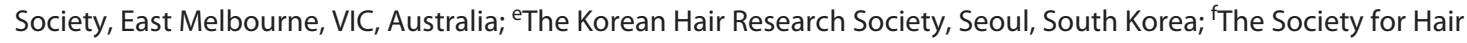 \\ Science Research, Tokyo, Japan
}

\section{Keywords}

Hair · Hair research $\cdot$ Alopecia $\cdot$ Hair follicle $\cdot$ Hair disorders ·

Scalp disorders · Dermatology

\begin{abstract}
The contributions of the core hair research societies and their members over the past 30 years have advanced the field of hair research and the understanding and treatment of hair disorders and normal hair growth.
\end{abstract}

(c) 2021 S. Karger AG, Base

\section{Introduction}

The past 3 decades have seen tremendous advances in the field of hair research, represented by the identification of hair follicle stem cells, the establishment of hair follicle immune privilege concept, the development of in vivo hair follicle reconstitution assays, and the deeper dissection of pathophysiology of hair loss disorders leading to the development of novel therapeutic approaches. These advances are due in large part to organized medicine [1].

The International Federation of Hair Research Societies (IFHRS) is a body comprising regional hair research societies. The 5 founding societies as described in this paper have worked independently within their regions and together on a global front to promote and fund research in hair disorders, encourage collaborations between researchers, and educate and disseminate information at conferences (Table 1).

The 5 hair research societies that make up the IFHRS include the following: Europe (European Hair Research Society; EHRS), the Americas (American Hair Research Society; AHRS), Japan (the Society for Hair Science Research; SHSR), Australasia (Australasian Hair and Wool Research Society; AHWRS), and Korea (Korean Hair Research Society; KHRS). In 2013, these 5 joined together to establish the IFHRS. Each society has distinctive activities and all hold regular events. However, the biennial World Congress for Hair Research, hosted by each society on a rotational basis, is the culmination of sharing the latest basic and clinical science and renewing friendships amongst this, the friendliest of research communities. It is to be noted that the following societies were accepted into the IFHRS in 2019: Ukrainian (Ukrainian Hair Research Society; UHRS), Chinese (Chinese Hair Research Society; CHRS)-provisional, and Russian (Russian Hair Research Society; RHRS)-provisional.

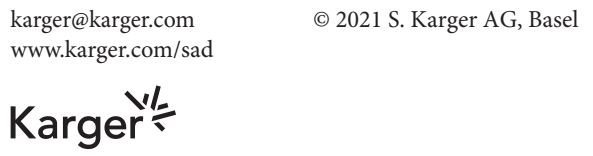


Table 1. World congresses for hair research

\begin{tabular}{llll}
\hline No. & Year & City & Hosting organization \\
\hline 1st & 1995 & Belgium & EHRS \\
2nd & 1998 & Washington DC & AHRS \\
3rd & 2001 & Tokyo & SHSR \\
4th & 2004 & Berlin & EHRS \\
5th & 2007 & Vancouver & AHRS \\
6th & 2010 & Cairns & AHWRS \\
7th & 2013 & Edinburgh & EHRS \\
8th & 2014 & Jeju & KHRS \\
9th & 2015 & Miami & AHRS \\
10th & 2017 & Kyoto & SHSR and JSCHR \\
11th & 2019 & Barcelona & EHRS \\
12th & 2022 & Melbourne & AHWRS \\
13th & 2024 & Americas & AHRS \\
14th & 2026 & Korea & KHRS \\
\hline
\end{tabular}

The European Hair Research Society, the oldest of the family of hair research societies, celebrated its 30-year anniversary in 2019 followed by the American Hair Research Society. This is not to say that hair research was invented in 1989. In fact, it is far from it! All those who have grown up in this exciting world of the hair follicle and fibre know that some of the earliest researchers made such an impact that they remain indexed in the reference list of many publications today.

\section{European Hair Research Society}

The EHRS was founded in 1989, and its first meeting was hosted by Dominique van Neste in Brussels with close to 40 participants from around Europe. Since then, the EHRS has hosted $>20$ hugely popular conferences, including 4 world congresses. Europe itself has also grown since 1989, and in recent years, the EHRS welcomed many members from Eastern Europe. Newly developing hair research societies in Ukraine and Russia demonstrate strong interest in the areas of basic and clinical science, and Tbilisi, Georgia, was the venue of the 17 th EHRS meeting in 2016.

Over the past 30 years, hair research has also developed considerably, and since 1983, the EHRS has recognized individuals who have made major scientific and clinical contributions through the prestigious John Ebling Lecture award (see Fig. 1). Early pioneers Colin Jahoda and Roy Oliver showed how important the dermal papilla is for hair regeneration. More recently, the EHRS introduced the Jürgen Schweitzer award for the best basic science lecture at the annual meeting. Hair research remains very strong in Europe with many research groups developing the next generation of hair researchers.

\section{American Hair Research Society}

The North American Hair Research Society (NAHRS) held its initial founders meeting on December 5, 1989, with a group of 13 dermatologists dedicated to furthering research in hair-related disorders. Today, it includes a diverse membership of clinicians, pathologists, clinical investigators, and basic scientists. It hosted the first USbased world congress in 1998 in Washington DC. This conference was one of the first to engage with the pharmaceutical industry as sponsors with several companies taking a strong interest in this research community, as the first solutions for alopecia were emerging, such as minoxidil. The hosting of the World Congress followed in 2007 (Vancouver) and 2015 (Miami).

The USA and Canada have seen very dramatic growth in hair research over the past 30 years with many notable pioneers. Many clinical researchers owe their knowledge and understanding to David Whiting, a renowned "father" of clinical hair research (see Fig. 2) who instilled the importance of the scalp biopsy in diagnosing causes of hair shedding. More recently, stem cell biology research "borrowed" the hair follicle after the significance of the "bulge" was proposed by George Cotsarelis in the early 1990s. Since then, these 2 worlds of research have collaborated to discover the key factors in hair follicle induction, now being leveraged for development of regenerative therapy.

The NAHRS became the first hair society to offer a mentoring program and also to offer companies the chance to obtain a "seal of recognition," ensuring robust science is employed in industrial research. In 2017, the society expanded to include North, Central, and South America and changed its name to "American Hair Research Society." To celebrate its expansion, the newly named AHRS held its first AHRS Summit in conjunction with the International Investigative Dermatology Meeting in Miami in May 2018. In addition, the AHRS organized sessions at the XII CILAD 2018 (Congresso Ibero Latinoamericano de Dermatologia) in São Paulo, Brazil, at the XXXVII RADLA (Reunion Annual de Dermatologos Latinoamericanos) in May 2019 in Buenos Aires, Argentina, and at Clube do Cabelo (Hair Club) of the XX Congresso de Cosmiatria in August 2019 in Rio de Janeiro, Brazil. 


\section{Society for Hair Science Research}

The Society for Hair Science Research (SHSR) was founded in 1993 aiming to advance research in hair biology and hair-related medicine in Japan, and it currently boasts a membership of around 100, comprising dermatologists, physicians interested in hair diseases, and researchers in academia/industries who are engaged in a broad range of fundamental research. Hideoki Ogawa is the founder and the first president, and he remains active in skin and hair research (see Fig. 3). An international Tokyo symposium on the Frontiers of Hair Research in 1993 brought many key scientists and clinicians to Japan heralding a strong future in international collaboration and setting the basis for the World Congress of Hair Research (WCHR). Many who were at that Tokyo meeting experienced both their first hair congress and first visit to Japan cementing relationships that have endured ever since.

In 1994, the Japanese Society for Clinical Hair Restoration (JSCHR) was also founded, and both SHSR and JSCHR members have led basic, clinical, and surgical research in Japan, with 2017 seeing them jointly host the highly successful 10th World Congress for Hair Research in Kyoto. The fields of hair restoration surgery and hair research have moved ever closer in all global regions. Basic scientist benefits from the clinical tissues made available by surgeons, and this branch of hair research has also been highly influential in the now developing area of regenerative therapy for hair loss.

\section{Australasian Hair and Wool Research Society}

The AHWRS was founded in 1995 at the suggestion of Rodney Dawber from the UK. The founding members were Rod Sinclair, George Rogers, Les Jones, Don Rivett, and Richard Shiell. In 1997, immediately before the World Congress of Dermatology held in Sydney, the AHWRS hosted an international meeting of hair research societies, formally bringing the wool and hair communities together for the first time. The AHWRS also hosted the 6th World Congress in 2010 held in Cairns.

The growth and commercial importance of the wool industry in Australia and New Zealand was a key driver in developing the founding basis for understanding fibre structure and texture as well as some of the earliest studies in the biology of the follicle. Early wool science pioneers worked at the Commonwealth Scientific and Industrial Research Organisation (CSIRO), the government- funded wool research institutes, and included Gordon Lennox and George Rogers (see Fig. 4). Wool research in the 1950s and 1960s came from a chemistry/biochemistry perspective, and much of today's knowledge about hair and wool fibre was developed from original studies on hair fibre protein analysis, structure, and interactions; the role of disulphide bonding; the links between cortical cell phenotype and fibre curl/crimp; and more latterly, the genetic basis for fibre shape.

The attempts to develop a biological defleecing agent in epidermal growth factor in the 1980s led to significant wool biology research in Australia with many subsequent discoveries in hair and wool biology coming from CSIRO divisions of protein chemistry and wool biology including early understanding of the hair cycle, the importance of the dermal papilla for hair induction, and models to study hair and wool follicles ex vivo. AgResearch in New Zealand has more recently led the field in fibre proteomics and structure and wool genetics.

\section{Korean Hair Research Society}

The Korean Hair Research Society (KHRS) was the most recent to be founded in 1998, originally as part of the Korean Dermatological Association (KDA) and then formally as an independent society in 2004. KHRS's founder Byung In Ro (see Fig. 5) was elected as the first president, and every 2 years, a group of presidents was elected, and now the 8th president is leading the KHRS.

The KHRS holds 2 large academic conferences annually: the KHRS meeting and the KDA symposium. In the hot summer, a hair forum is held every year in the academic city of Daejeon to discuss hair diseases. At each academic conference, dermatologists, foreign guest speakers, pharmaceutical companies, medical equipment companies, and basic hair researchers from Korea all participate in the presentations and discussions.

An annual Hair Forum provides a means for informal discussion, and continuing education events are held every year together with public facing events, such as the "green hair campaign." The Korean hair research community has taken the lead in the development of an alopecia scoring system - known as a basics and specific classification system - that better reflects the global diversity in patterns of hair loss and with 1 scale for both males and females.

The immediate past president, Won Soo Lee, has championed hair research in Korea and also ensured that the hair research community in Korea would host inter-
Westgate/Bergfeld/Ceh/Hordinsky/ Sinclair/Piraccini/Kang/Ohyama 
national meetings in the rotation. In 2014, the 8th World Congress for Hair Research was beautifully hosted in Jeju Island, a spectacular volcanic island that left the participants with some "forever" memories.

\section{Future Prospects in Hair Research}

In-depth understanding of the mechanisms enabling hair follicle development, epithelial, melanocyte, and dermal stem cell survival, hair cycle regulation, cell kinetics, and immunological crosstalk to maintain the homeostasis of the hair follicle enhances the significance of hair research not limited to the management of intractable hair disorders. The hair follicle is regarded as one of the most ideal mini organs to tackle key biological questions in other organ systems.

In view of conquering severe hair diseases, including primary scarring alopecia, alopecia areata universalis/totalis, and advanced male/female pattern baldness, the essential technical basis seems to be nearly established. Partial regeneration of hair follicle (-like) structures using human hair follicle stem/progenitor cells or induced pluripotent stem cells has been reported. The elucidation of IFN-gamma-IL15 axis in alopecia areata by genomics, bioinformatics, and pharmacological approaches has led to the discovery of JAK inhibitors as promising medications. The dissection of etiopathogenesis of lichen planopilaris adopting genetically engineered animal models has revealed the involvement of the PPAR-gamma pathway. Additional new insights into the pathophysiology of various hair loss conditions, for instance, a possible association between sunscreen and frontal fibrosing alopecia, have been reported.

The next 3 decades would be the term to bring what has been developed at bench to clinics. Prevailing recognition that treating hair diseases is time consuming, laborious, and less efficient will be abandoned. Advances in bioimaging, omics, and artificial intelligence technology should enable the assessment of the pathophysiology of individual patients, which should allow the optimization of treatment plans consisting of regenerative medicine and immunomodulation techniques.

The future of hair research is full of hope. Most conditions that are currently unmanageable would become, at least, controllable. Perhaps, there will be a definitive solution for androgenetic alopecia and other major hair loss conditions before 2050, granted that current activities in basic and clinical hair research are sustained. The IFHRS will endeavour to achieve this forecast.

Thirty Years of Hair Research Societies

\section{Profiles of Some Key Hair Researchers}

Fig. 1. John Ebling, $\mathrm{DSc}, \mathrm{PhD}$, FIBiol.

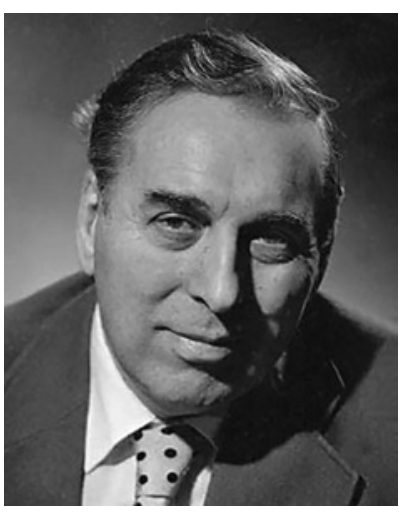

Francis John Govier Ebling (Fig. 1)

Francis John Govier Ebling, DSc, PhD, FIBiol 19181992, Professor of Zoology (1968-1983), and Emeritus Professor in the Sub-Department of Dermatology (19831992) at the University of Sheffield. John made so many fascinating contributions to our understanding of hair biology and physiology, and his perspective as a zoologist and social, developmental, and evolutionary scientist was inspiring to the many people who knew him and studied with him.

Fig. 2. David A. Whiting, MD.

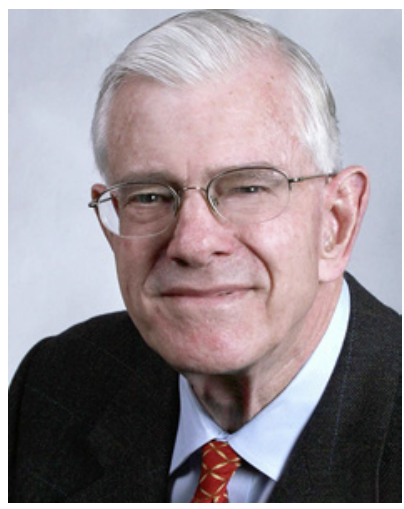

David A. Whiting (Fig. 2)

David Ashby Whiting, MD, 1932-2018, was a renowned dermatologist and expert in alopecia. Highly respected member of the worldwide hair research community and first recipient of the AHRS David A. Whiting MD Leadership and Research Award, which recognizes and honours a clinician and/or researcher who has been a significant contributor to advancing the science and understanding of hair disorders. David also loved jazz and would always be found on the dance floor with his wife Harriet at conferences. 
Fig. 3. Hideoki Ogawa, MD, PhD.

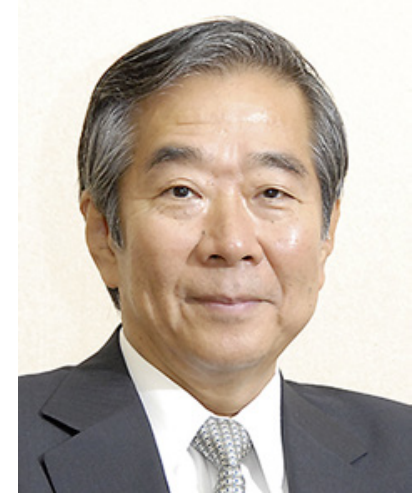

\section{Hideoki Ogawa (Fig. 3)}

Hideoki Ogawa, $\mathrm{MD}, \mathrm{PhD}$, is currently the CEO of Juntendo University and is an internationally renowned dermatologist and the founding Editor-in-Chief of the Journal of Dermatological Science (1990-1993). He is the founder of the Society for Hair Science Research (SHSR) and still anxiously supports its activity as the honorary director. In addition to his vast scientific contributions in hair biology and other fields of dermatological science, he is distinguished by his provision of the occasion for the very first International Meeting of Hair Research Societies in Tokyo, which set the basis for the World Congress of Hair Research (WCHR). He hosted the 3rd and 10th WCHR (in Tokyo and in Kyoto) in 2001 and 2017, respectively. His internationality has been further enhanced by his accepting and mentoring many oversea dermatologists and researchers at his institute.

Fig. 4. George Rogers (left) and Rodney Sinclair (right).

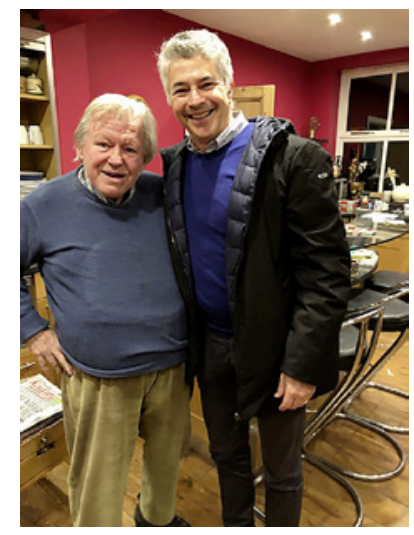

George Rogers (Fig. 4)

Prof. George Rogers was the first President of the AHWRS. George left school in 1943 at the age of 15 to work as a laboratory assistant, but his talents were quickly rec- ognized, and he was encouraged to complete his schooling at night. He ultimately graduated from the University of Melbourne with a Bachelor of Science and Masters in Biochemistry. His masters project led to a single author Nature paper in 1952 on purification of the polypeptide hormone secretin. He did his $\mathrm{PhD}$ at Cambridge and returned to Australia becoming chair in biochemistry at Adelaide University.

George had a long and distinguished career in wool science culminating in his election to the Australian Academy of Science in 1977. Major highlights include the identification of citrulline in the hair inner root sheath. $\mathrm{He}$ described how arginine is converted to citrulline through posttranslational modifications, and he discovered the enzyme arginine deaminase that was later found to play a major role in the pathogenesis of both rheumatoid arthritis and multiple sclerosis. A PubMed search reveals $>50,000$ publications on the topic. George described the structure of alpha-keratin (1959), amino acid metabolism in wool roots (1959), molecular organization in a-keratin (1959), the occurrence of citrulline in proteins (1962), separate synthesis of fibrillar and matrix proteins in the formation of keratin (1963), a suggested nomenclature for keratin and keratin-like products of cells (1964), and keratin protofilaments from hair follicles (1965).

Other major contributions included the discovery of the nature of trichohyalin, the production of the first transgenic sheep that overexpressed keratin proteins (to alter wool properties such as lustre, crimp, and felting), and the production of the cloned sheep Matilda (second after Dolly in the UK). George remains active in hair biology, and the George Rogers oration is given at each AHWRS conference by the most meritorious Australian researcher.

Fig. 5. Byung In Ro.

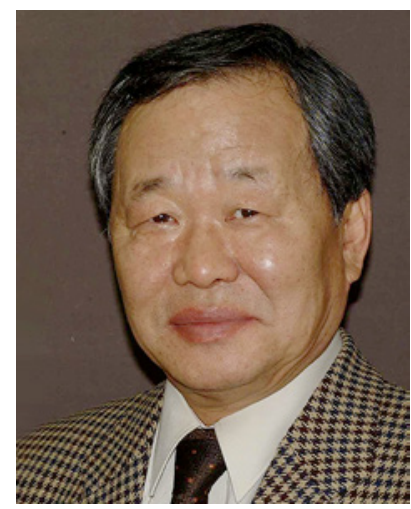

\section{Byung In Ro (Fig. 5)}

Byung In Ro was the first KHRS president to play a major role in the creation of the KHRS in 2004. He has
Westgate/Bergfeld/Ceh/Hordinsky/ Sinclair/Piraccini/Kang/Ohyama 
had many achievements in basic and clinical research in hair loss disorders in Korea. Although he is now 75 years old, he is still actively treating hair loss patients.

\section{Q\&A from Key Persons in the Societies}

\section{American Hair Research Society}

Fig. 6. Elise A. Olsen, MD.

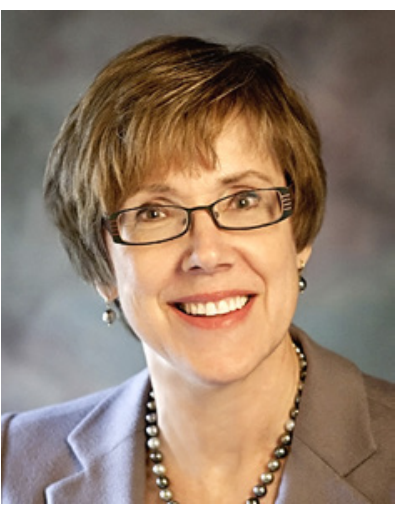

Elise A. Olsen, MD (Fig. 6)

Professor of Dermatology and Medicine; Director, Cutaneous Lymphoma Research and Treatment Center; Director, Hair Disorders Research and Treatment Center; Director, Dermatopharmacology Study Center; Duke University Medical Center, Raleigh, NC, USA.

\section{How did you get into hair research?}

When I began as a new faculty member at Duke, I created the Dermatopharmacology Study Center, and my first clinical trial was principle investigator on $2 \%$ topical minoxidil in MPHL [male pattern hair loss] with 150 subjects. I quickly was dubbed the "hair expert" at Duke, and all hair consults came to me thereafter. Approval of $2 \%$ topical minoxidil was followed by a nationwide teleconference on topical minoxidil with such luminaries as Wilma Bergfeld and Terry Headington on the panel. I have been involved in clinical research on hair disorders since that time.

\section{What has been your career highlight?}

I have 2 highlights: the first is the publication of 2 editions of my textbook, Hair Disorders: Diagnosis and Treatment, and the second is creation of various "Think Tanks" with my colleagues to create new ways of assessing, collecting data, and publishing our findings on various hair disorders.

Thirty Years of Hair Research Societies
3. What, in your opinion, has been the most important research finding from the past 30 years?

I think the fundamental understanding of the role of the bulge and stem cells and the molecular events driving various elements of the hair cycle are the most important advances.

4. How has being part of the global hair research community helped you in your research/career/clinical practice?

No one person working in isolation can make the kind of contribution made by working with a group of experts. Harnessing different ideas and ways of looking at things and knowing what others have done in a given area that perhaps has not yet been published can move knowledge forward at a much greater pace than working alone or at a single site. I have certainly found that to be the case with hair disorders. Plus, getting to know and work with people across the globe who share my passion for research in hair disorders has been so enjoyable and uplifting.

5 . What is your advice to a young person who might be interested in hair research?

For those clinicians who see a possibility of doing clinical research, I think the first thing is to determine what is unknown about a given condition and sort out whether a protocol collecting data in your clinic can help to move things forward. Adding on site-related specific studies, both clinical and basic science, to sponsor funded studies can help to relieve the financial burden of research. And, engaging partners to work with you, particularly those who are senior, in related fields or who can be a mentor, is wise.

Fig. 7. Jerry Shapiro, MD.

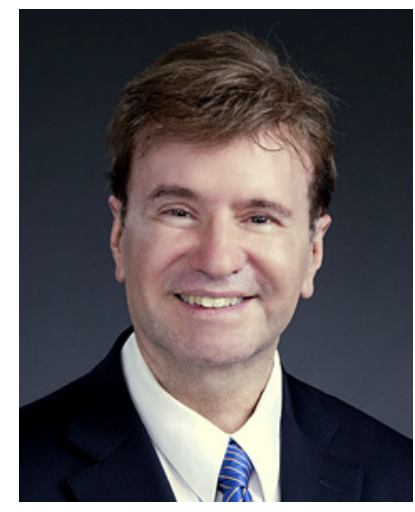

Jerry Shapiro, MD (Fig. 7)

Professor, the Ronald O. Perelman Department of Dermatology, New York University School of Medicine, New York, NY, USA.

Skin Appendage Disord 2021;7:90-107 DOI: $10.1159 / 000512035$ 
1. How did you get into hair research and what has been your career highlight?

I saw a need in 1986 after my dermatology residency that there was no one in Canada and very few in the USA/ worldwide focusing on medical hair restoration. Very few people had the breadth of knowledge to treat difficult scalp disorders. I had a passion for these disorders. My career highlight has been training over 30 hair dermatology fellows all of whom are spread over 4 continents. Each has spent 1 year with me. They have disseminated the knowledge I have taught them and are constantly thinking of ways to improve the field and making it even better. This has been my most important legacy: teaching the next generation.

2. What, in your opinion, has been the most important research finding from the past $\mathbf{3 0}$ years?

Techniques for measurement of hair density and calibre that can be used quickly in the office setting. In addition, JAK inhibitors for alopecia areata, platelet-rich plasma for androgenetic alopecia, potent antiandrogens for pattern hair loss, and follicular unit excision for hair transplantation.

3. How has being a part of the global hair research community helped you in your research/career/clinical practice?

Collaborations have been pivotal in my career. I have collaborated internationally with 6 continents of researchers. I learn so much from my colleagues from around the world.

4. Tell us your best memory from attending a World Congress for Hair Research?

Vancouver 2007. I was president of that meeting. I learned a lot in my own hometown from so many of my international colleagues. All my fellows were there to help celebrate the meeting in Vancouver.

5. What is your advice to a young person who might be interested in hair research?

You must have a passion for it. On the clinical side, you must have patience and understand the feelings of every patient whom you encounter. You need to consider all treatment options and try to deduce the best treatments based on evidence-based medicine if it exists. For a clinician, just jump right into it and get a feel for what works and what does not. As a researcher, go ahead and test your hypotheses. You must create bridges with other clinicians and basic scientists.
Fig. 8. Antonella Tosti, MD.

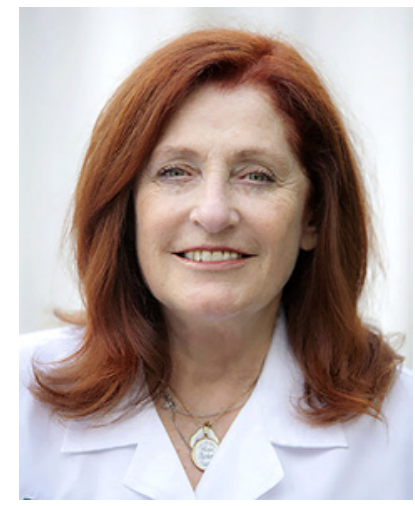

Antonella Tosti, MD (Fig. 8)

Fredric Brandt Endowed Professor of Dermatology, Dr. Phillip Frost Department of Dermatology and Cutaneous Surgery, University of Miami Miller School of Medicine, Miami, FL, USA.

1. How did you get into hair research and what has been your career highlight?

I became interested in hair biology when I was very young, during my high school, as I was so fortunate to meet a pioneer on the study of the hair follicle, Dr. William Montagna, who was a family friend. I spent a few months with him in Portland during my residency, and this is still a fantastic memory for me. When I became a dermatologist, I studied hair disorders by myself, and I started a clinic dedicated to hair disorders at the University of Bologna in 1982, the very first hair clinic in the world, as there were very few people interested in hair at that time. I was among the founders of the European Hair Research Society (EHRS) in 1989 and the president of the society in 2009. I was full Professor in Bologna until 2010, when I moved to Miami and became Professor of Dermatology at the University of Miami. I am a clinician, and I love to interact and treat hair patients; I know they can be difficult, but at the end, I believe that I learned from them most of the things I know. I trained hundreds of dermatologists from all around the world, and I am proud to say that many of them are today recognized as experts in hair disorders.

2. What, in your opinion, has been the most important research finding from the past 30 years?

Identification and characterization of hair follicle stem cells.

3. How has being a part of the global hair research community helped you in your research/career/clinical practice?

I made many friends through the hair community, everyone taught me something, and many showed me a new
Westgate/Bergfeld/Ceh/Hordinsky/ Sinclair/Piraccini/Kang/Ohyama 
part of the world, as I have travelled worldwide thanks to them. A friend I particularly love is Dr. David Whiting, and I now miss his expertise and friendship a lot as I often discussed with him my projects and ideas.

4. Tell us your best memory from attending a World Congress for Hair Research?

Probably being part of the organizing Committee in Miami. I was so welcome from the NAHRS, now AHRS, when I moved to the US!

5 . What is your advice to a young person who might be interested in hair research?

If interested in clinical research: learn trichoscopy!

\section{European Hair Research Society}

Fig. 9. Ulrike Blume-Peytavi, MD.

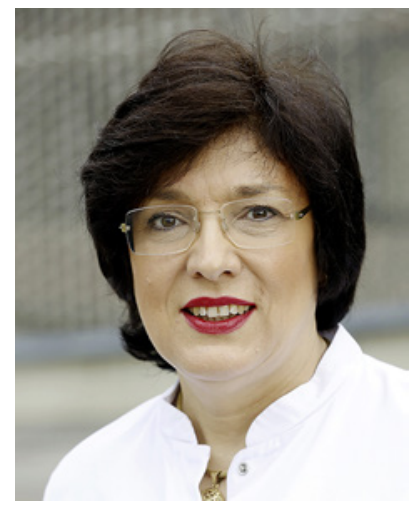

Ulrike Blume-Peytavi, MD (Fig. 9)

University Professor of Dermatology; Vice Director, Department of Dermatology and Allergology, CharitéUniversitätsmedizin Berlin; Director, Clinical Research Center for Hair and Skin Science, Berlin, Germany.

1. How did you get into hair research and what has been your career highlight?

My career highlight has been the foundation of my Clinical Research Center on Hair and Skin Science in 2003 and the hosting and organization of the World Congress of Hair Research Societies in Berlin in 2004.

2 . What, in your opinion, has been the most important research finding from the past $\mathbf{3 0}$ years?

As a founding member of the European Hair Research Society (EHRS) in 1989, I was nearly from the beginning of my career involved in the network of hair researchers and clinicians. Annual meetings and scientific exchanges, friendships over the many years contributed significantly to the inspirations, enthusiasm, and continuous efforts to further advance our projects in hair, hair disorders, and translational developments.

Thirty Years of Hair Research Societies
3. How has being a part of the global hair research community helped you in your research/career/clinical practice?

Inspiration, enthusiasm, creativity, new ideas for research projects all have been nourished by this.

4. What is your advice to a young person who might be interested in hair research?

Join an annual meeting of a hair research society or a world congress for hair research to be inspired and make the right decision.

Fig. 10. Colin Jahoda, MD.

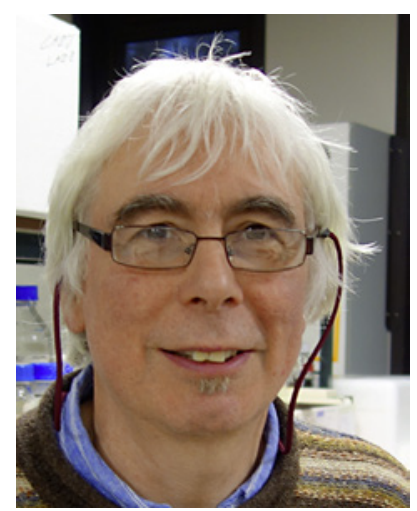

Colin Jahoda, MD (Fig. 10)

Professor, Durham University, Durham, United Kingdom.

1. How did you get into hair research and what has been your career highlight?

I was very fortunate to be taught by Roy Oliver at Dundee University in Scotland and did an undergraduate project in his lab. After graduating, I was aiming to do research into animal behaviour but happened to meet Roy in a pub, and he asked if I wanted to do a PhD on whisker follicles, and I jumped at it. I can't pick out a career highlight; I hope it's still to come. However, having my first paper, on growing dermal papilla cells, rejected by the JID for "lack of interest" was certainly a strong driver.

2. Tell us your best memory from attending a World Congress for Hair Research?

Most definitely meeting Angela Christiano at the first World Congress in Seville. It was a very exciting meeting, and I was bowled over by Angela's enthusiasm and fresh approach to hair research. It led to a long standing and very fruitful collaboration, at least for me.

3 . What is your advice to a young person who might be interested in hair research?

First, I would say "go for it," as the hair follicle is one of the most fascinating systems in biology; there are endless

Skin Appendage Disord 2021;7:90-107 DOI: $10.1159 / 000512035$ 
questions to ask. Second, I would suggest that they really take some time becoming friends with the hair follicle before they start to study the more detailed aspects of the system. The most interesting findings/results are going to have the most general significance. Third, I would pass on Roy Oliver's advice to me: try not to pay too much attention on what other people are doing and focus on your own ideas. Finally, I would tell them not to be frightened to challenge orthodoxy, and especially to have fun.

Fig. 11. Abraham Zlotogorski, MD

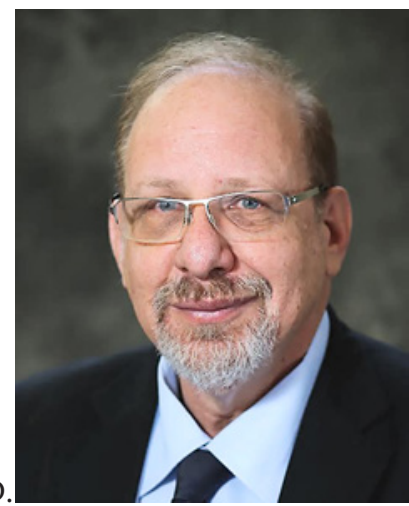

Abraham Zlotogorski, MD (Fig. 11)

Professor and Chair, Department of Dermatology, Hadassah-Hebrew University Medical Center, Jerusalem, Israel.

1. How did you get into hair research and what has been your career highlight?

Before I completed my residency, I asked my chair to do my sabbatical in basic and clinical hair research. My boss agreed, but he asked me: What will you do with this? More than 25 years elapsed, and I don't regret my decision. My initial interaction with Kurt Stenn and Angela Christiano opened for me a fascinating world, which later progressed to a road full of excitements and ongoing discoveries, not ended yet.

My career highlight was my ability to help patients to cope with the distress associated with hair loss and make them happier. In terms of basic science studies, I was lucky to be involved in the discovery of several genotrichoses. In terms of hair research community, I helped in closing the gap between the Western and Eastern European worlds of research, by bringing the Russian, Ukrainian, and Georgian hair research societies to become part of the European Hair Research Society.

2 . What, in your opinion, has been the most important research finding from the past $\mathbf{3 0}$ years?

The discovery of JAK inhibitors for the treatment of alopecia areata, which is based on better understanding of the pathogenesis along with unique observations in my clinic and other clinics around the world. This revolutionary treatment for alopecia areata is changing the lives of thousands of patients around the globe.

3. What is your advice to a young person who might be interested in hair research?

Don't hesitate, go for it! In your lab, be professional, look for the truth, and see the person behind the pipette. When you come to the clinic, listen to the patient, offer the patient hope and humour, and stay away from fake discoveries.

\section{Society for Hair Science Research}

Fig. 12. Taisuke Ito, $\mathrm{MD}, \mathrm{PhD}$.

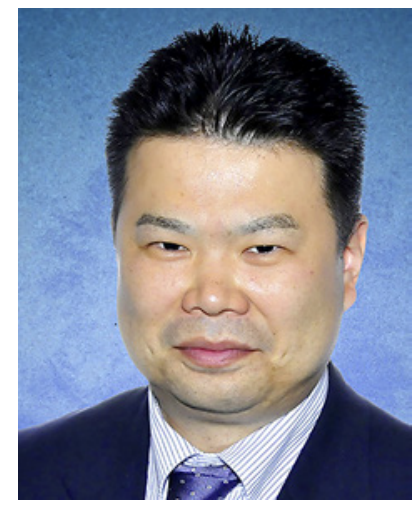

Taisuke Ito, MD, PhD (Fig. 12)

Associate Professor, Department of Dermatology, Hamamatsu University School of Medicine, Hamamatsu, Shizuoka, Japan.

1. How did you get into hair research and what has been your career highlight?

When I was the senior resident, I was asked to take care of the model mouse of cicatricial alopecia (NZB/KN) by Dr. Fukumi Furukawa (at that time, Dr. Furukawa was Associate Professor of Department of Dermatology, Hamamatsu University School of Medicine). During taking care of them, I took an interest in autoimmune hair loss diseases, and I was allowed to start MRL/lpr mouse that is the model for alopecia of SLE [systemic lupus erythematosus].

2. What, in your opinion, has been the most important research finding from the past 30 years?

The most important finding may be NKG2D that is the key molecule of the pathogenesis of alopecia areata. NKG2D-expresssing cytotoxic $\mathrm{T}$ cells produce amount of IFN-g that can be inhibited by JAK inhibitor.

3. How has being a part of the global hair research community helped you in your research/career/clinical practice?
Westgate/Bergfeld/Ceh/Hordinsky/ Sinclair/Piraccini/Kang/Ohyama 
It is really helpful for me. I have found lots of friends from many countries, and they kindly discuss my idea for experiments with me. In my opinion, the hair research community has a very warm and friendly atmosphere.

4. Tell us your best memory from attending a World Congress for Hair Research?

Of course, we had held WCHR2017 in Kyoto. I was a member of the program committee. In other WCHRs, I had an opportunity to give a key lecture and chair the WCHR 2015 held in Miami, USA. It was a best memory from attending WCHR.

5. What is your advice to a young person who might be interested in hair research?

Hair follicle tissue has dynamic and histological changes as hair cycles. This is the dramatic and very unique character that was not shown in other tissues. In addition, hair follicles largely take part in immune reactions. The hair follicle still has a lot of aspects that should be studied.

Fig. 13. Manabu Ohyama, $\mathrm{MD}$, $\mathrm{PhD}$.

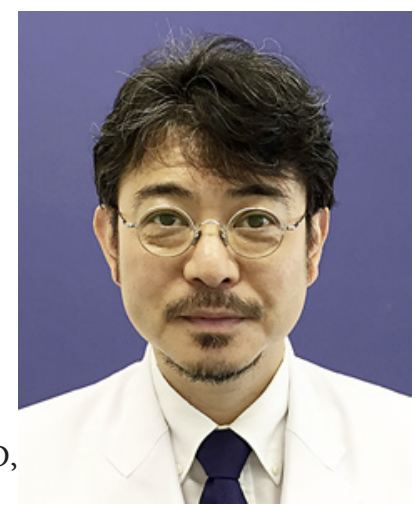

Manabu Ohyama, MD, PhD (Fig. 13)

Professor and Chair, Department of Dermatology, Kyorin University Faculty of Medicine, Mitaka City, Tokyo, Japan.

1. How did you get into hair research and what has been your career highlight?

When I was a postdoctoral fellow at Dermatology Branch, NCI, NIH, I carried out a research project aiming to identify biomarkers for human hair follicle stem cells and was greatly fascinated by the precision of the machinery maintaining the hair follicle homeostasis. At the same time, as a clinician, I had noticed that hair loss diseases are often intractable. I was convinced that hair research should be my area of expertise. Probably, the identification of CD200 as a cell surface marker enabling the isolation of human bulge cells would be the most notable contribution that I have made to the field.

Thirty Years of Hair Research Societies
2. What, in your opinion, has been the most important research finding from the past 30 years?

I would say that the discovery of the hair follicle bulge as the niche for multipotent epithelial stem cells by Prof. George Cotsarelis and colleagues (Cotsarelis et al., Cell, 1990) would be the most seminal work in the last 3 decades. The work accelerated our understanding of hair follicle biology and the development of regenerative medicine and facilitated the etiopathogenesis of intractable hair loss diseases, such as scaring alopecia.

3. How has being a part of the global hair research community helped you in your research/career/clinical practice?

I truly enjoy the privilege of being a part of it.

4. Tell us your best memory from attending a World Congress for Hair Research?

I served as the chair for the scientific program committee for WCHR2017 in Kyoto.

5. What is your advice to a young person who might be interested in hair research?

Hair research contains variety of interesting topics, those related to developmental and stem cell biology, regenerative medicine, immunology, endocrinology, cosmetology, biochemistry, pharmacology, and so on. There are still so many unknowns, and one can surely contribute to the field. As hair loss greatly impacts on the life of affected individuals, the researcher focusing on the diseases should be able to feel that he/she is doing something for others.

Fig. 14. Yutaka Shimomura, $M D$, $\mathrm{PhD}$.

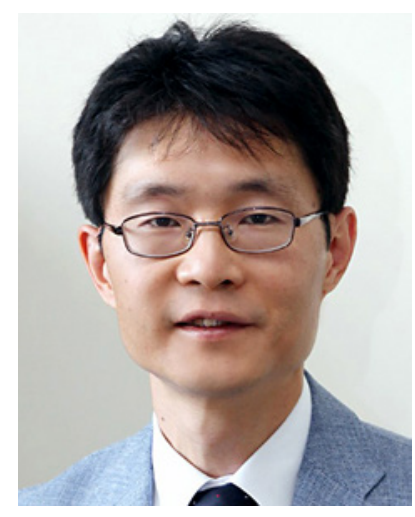

Yutaka Shimomura, MD, PhD (Fig. 14)

Professor and Chair, Department of Dermatology, Yamaguchi University, School of Medicine, Ube, Yamaguchi, Japan.

1. How did you get into hair research and what has been your career highlight?

When I was a medical student in Niigata University, Japan, I had been deeply impressed by lectures from Prof.

Skin Appendage Disord 2021;7:90-107 
Masaaki Ito, who was a specialist in hair research. Then, I decided to become a dermatologist and started research of hair biology.

2 . What, in your opinion, has been the most important research finding from the past $\mathbf{3 0}$ years?

The most important finding will be that Prof. George Cotsarelis identified the niche of hair follicle stem cells in the bulge portion in 1990 (Cotsarelis et al., Cell, 1990).

3 . How has being a part of the global hair research community helped you in your research/career/clinical practice?

It is definitely helpful for me because I am able to significantly update my knowledge in both clinical and research aspects. In addition, through attending the WCHR, I can meet many friends and colleagues from other countries.

4. Tell us your best memory from attending a World Congress for Hair Research?

I had an opportunity to give a keynote lecture in the WCHR2010 that was held in Cairns, Australia. It was the best memory and the greatest honour for me.

5 . What is your advice to a young person who might be interested in hair research?

I always tell medical students and young dermatologists that we can extract genomic DNA, total RNA, and proteins even from 1 plucked hair and perform a series of experiments following the central dogma, that is, we may find something new from 1 plucked hair. Such experiments cannot be done in other research fields.

\section{Korean Hair Research Society}

Fig. 15. Gwang Seong Choi, MD, $\mathrm{PhD}$.

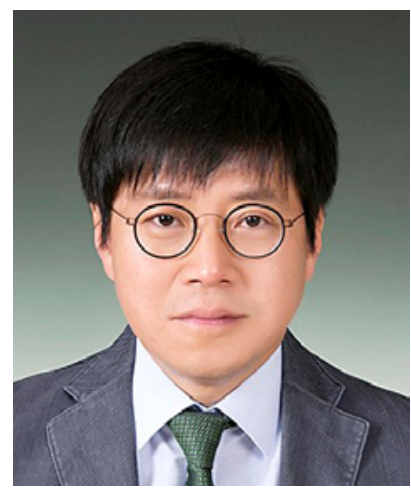

Gwang Seong Choi, MD, PhD (Fig. 15)

Professor and Chairman, Department of Dermatology, Inha University College of Medicine; Director of Medical Center Branch, Inha University Research and Business Foundation; and Chairman of IRB, Inha University Hospital, Incheon, Korea.
1. How did you get into hair research and what has been your career highlight?

I got involved in the hair research society in Korea and also globally after attending the EHRS meeting in Marburg, Germany, in 2000. The EHRS meeting gave me new insight and vision into hair research.

2. What, in your opinion, has been the most important research finding from the past $\mathbf{3 0}$ years?

I personally think that the finding of finasteride to be effective for the treatment of MPHL was the most important. Through this finding, dermatologists have gained a powerful and effective method to solve the most common hair loss disease, and many new researchers joined in the field of hair research.

3. How has being a part of the global hair research community helped you in your research/career/clinical practice?

It has truly helped me greatly. I started out as a member of the Korean Hair Research Society. And, as I took part in the global hair research community, I gained upto-date knowledge on research and methods to cure and treat patients.

4. Tell us your best memory from attending a World Congress for Hair Research?

I served as the director of the Financial Committee for the WCHR 2014 in Jeju meeting.

5 . What is your advice to a young person who might be interested in hair research?

The field of hair research is an area worth looking into as it includes stem cells, tissue regeneration, and inflammation. There are also a large number of patients who are suffering from hair loss, so research by clinicians is in great need.

Fig. 16. Hoon Kang, $\mathrm{MD}, \mathrm{PhD}$.

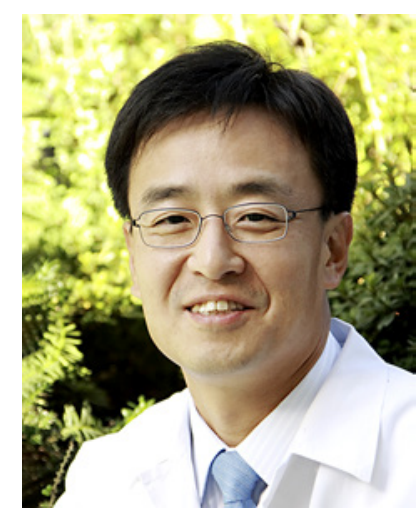

Hoon Kang, MD, PhD (Fig 16)

Professor, Head of Department, Department of Dermatology, Eunpyeong St. Mary's Hospital, College of 
Medicine, The Catholic University of Korea, Seoul, Korea.

1. How did you get into hair research and what has been your career highlight?

Since becoming a dermatologist, I started stem cell research about 20 years ago to regenerate skin. At that time, I learned that hair follicle cells can be an important source of skin regeneration, and naturally I entered the field of hair research by doing various experiments with hair follicle cells. Although I did not perform well in my career, I still remember that I developed a Korean trichoscopy operation program that clinically measures the number of hairs, hair caliber, texture, and growth rate. And, it is most memorable that many papers were submitted through basic field research using dermal papilla cells.

2. What, in your opinion, has been the most important research finding from the past $\mathbf{3 0}$ years?

There are 2 main things that come to mind. The first is that although not all of the mechanisms for alopecia areata have been identified, one has, and that is that this autoimmune disease is caused by the collapse of immune privilege by $\mathrm{CD} 8^{+} \mathrm{NKG} 2 \mathrm{D}^{+} \mathrm{T}$ cells. The second is that oral medicines have been developed for the treatment of androgenetic alopecia. It has been demonstrated that DHT is related to the progression of androgenetic alopecia and that the $5 a$-reductase inhibitor treatment has the effect of inhibiting the progress of hair loss.

3. How has being a part of the global hair research community helped you in your research/career/clinical practice?

By actively participating in WCHR, EHRS, and NAHRS meetings held regularly, I was able to obtain various hair research-related information. In addition, as a meeting with many scholars in the field of hair research, personal communication became a chance to broaden the knowledge. I would also like to share my gratitude for the young researchers I met at the WCHR.

4. Tell us your best memory from attending a World Congress for Hair Research?

It is most memorable that I participated in the 8th WCHR held in Korea in 2014 as a scientific preparatory director of the organizing community and finished the WCHR well. Also, I can't forget that I participated in the 5 th WCHR and made an oral presentation when I was going to Dr. Jerry Shapiro (UBC, Vancouver) to study hair care and research for 2 years.

5 . What is your advice to a young person who might be interested in hair research?

There are still many unknown areas of hair biology fields. The theme of hair is not directly related to life, and it doesn't make any big changes right away, so it can be less fun. But hair follicles are exciting cells that have infinite focus and show a variety of molecular biological changes and consequences. If you interact frequently with many hair researchers based on consistency and sincerity, you will find yourself in a new field of hair research that you don't know.

Fig. 17. Woo-Young Sim, MD.

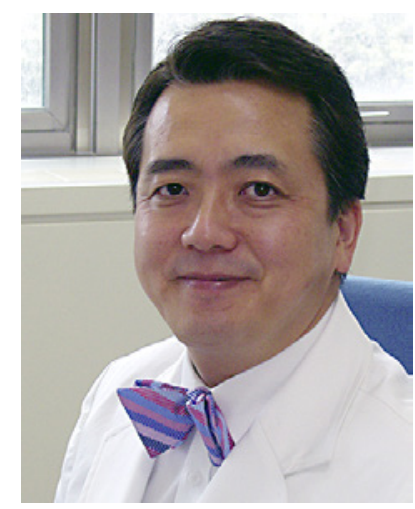

Woo-Young Sim, MD (Fig. 17)

Department of Dermatology, College of Medicine, Kyung Hee University, Seoul, Korea.

1. How did you get into hair research and what has been your career highlight?

Attending a lecture on hair biology by Professor Chull-Wan Ihm as a resident of dermatology ignited my interest in the particular specialty. After finishing residency and while pondering what I would like to do in the future with my career, I realized that there weren't many dermatologists specializing in hair and not enough studies on the subject. As I began to attend hair research conferences, I became more interested in hair research. Meanwhile, I started to see more patients with hair disorders. The rapid industrialization of South Korea over the past 30 years has significantly transformed our dietary patterns and the environment. The emergence of new disease patterns is also a consequence. These changes include dermatological disorders, including atopic dermatitis and alopecia areata, which have become common diseases. It is well known that alopecia totalis is difficult to cure, and I start treatment after informing the patients with alopecia totalis that the prognosis will not be good. Around 1990, I had a 30-year-old female patient who started with alopecia areata and progressed to total hair loss in only 3 months. However, about 4 months after application of diphenylcyclopropenone to the half side of the scalp, hair regrowth on both sides was observed. The patient's recovery was exceptional and dif- 
ferent from what I had experienced in the past. Since this case, I have had similar results for many years. Based on the data I had collected, I wrote a research paper titled "Acute Diffuse and Total Alopecia" in 2009. Even these days, patients with similar symptoms experience hair regrowth without treatment.

2. What, in your opinion, has been the most important research finding from the past 30 years?

A genome-wide association study which showed a strong association of predisposition to alopecia areata with certain polymorphisms of ligands for the natural killer cell-activating receptor NKG2D is one of the most important findings. Based on these findings, many studies showed that $\mathrm{CD} 8^{+} \mathrm{NKG} 2 \mathrm{D}^{+} \mathrm{T}$ cells are the major effectors of alopecia areata pathogenesis. These findings provided the rationale for therapeutically targeting JAK kinases.

3. How has being a part of the global hair research community helped you in your research/career/clinical practice?

Most people would have the same opinion as mine. Going to a global hair research conference is always exciting and inspiring. I learn wonderful things from speakers at the conferences, and can share lots of ideas with the other attendees. I often finish the day feeling ready to try new experiments and decide to take some steps to bring this excitement and ideas back to my research and clinical practice.

4. Tell us your best memory from attending a World Congress for Hair Research?

I remember the hair research meeting I attended in Miami, Florida, in 2015. At that time, I was worried about an increase in the number of patients with rare recovery from alopecia totalis, and I felt excited about the news that tofacitinib had a significant effect on it. I also realized that a lot of researchers have discovered the pathogenesis for the disease and found new drugs.

5. What is your advice to a young person who might be interested in hair research?

Especially in the field of hair biology, there are so many things to study, and further studies are required to discover pathogenesis of hair disorders. I believe that there is potential for effective therapy for our patients as long as we continue to engage in research to discover new insights and pioneer relevant findings. I hope we open doors to future development in cures for hair disorder.

See Figs. 18-22 for a look at all of the societies and the IFHRS.

\section{Statement of Ethics}

We attest we have authorization to include the photos with persons' images including event attendees who were given due notice of photographic activity and potential reuse of images.

\section{Conflict of Interest Statement}

The authors have no conflicts of interest to declare.

\section{Funding Sources}

There was no funding source for this article.

\section{Author Contributions}

Gill Westgate, $\mathrm{PhD}$, wrote the majority of the original draft of the paper. Wilma F. Bergfeld, MD; Victoria Ceh, MPA; Maria Hordinsky, MD; Rodney Sinclair, MBBS, MD, FACD; Bianca Maria Piraccini, MD; Hoon Kang, MD, PhD; and Manabu Ohyama, MD, $\mathrm{PhD}$, participated in the writing of the paper.

\section{Reference}

1 Westgate GE, Bergfeld WF, Ceh V, Hordinsky M, Sinclair R, Piraccini BM. Thirty years (and more) of hair research societies. J Am Acad Dermatol. 2019 Aug;81(2):652-3. 



Fig. 18. Americas. A Program cover from WCHR2015 Miami. B Attendees of WCHR2015. C WCHR2015 Program Co-Chairs, Drs. Wilma Bergfeld, Maria Hordinsky, and Angela Christiano, presented with program chair awards from Dr. Ken Washenik. D WCHR2015 hair follicle confocal images. E Dr. Pantelis Rompolas lecturing during the WCHR2015. F Expert table on central centrifugal cicatricial alopecia, hosted by Drs. Valerie Callender (far right) and Nonhlanhla Khumalo (center). 


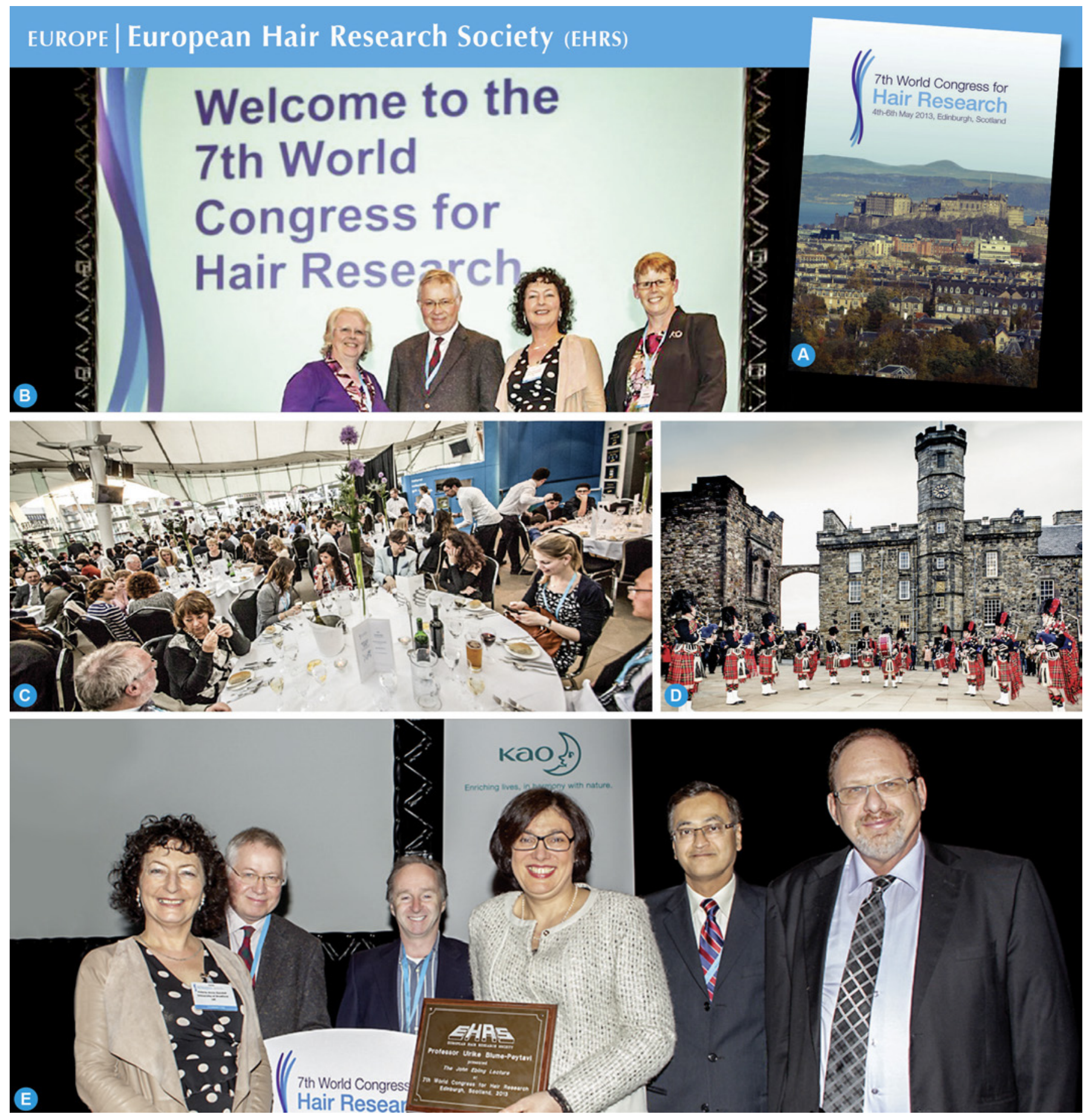

Fig. 19. Europe. A Program cover from WCHR2013 Edinburgh. B WCHR2013 travel award recipient with Congress organizers - Profs. Andrew Messenger (Congress President), Valerie Randall (Scientific Chair), and Gillian Westgate (Congress Secretary). C Attendees of WCHR2013 Congress dinner at Dynamic Earth, Edinburgh. D WCHR2013 entertainment of traditional Scottish pipe band. E 2013 John Ebling Lecture Award presented to Dr. Ulrike Blume-Peytavi (center) at the WCHR2013. 


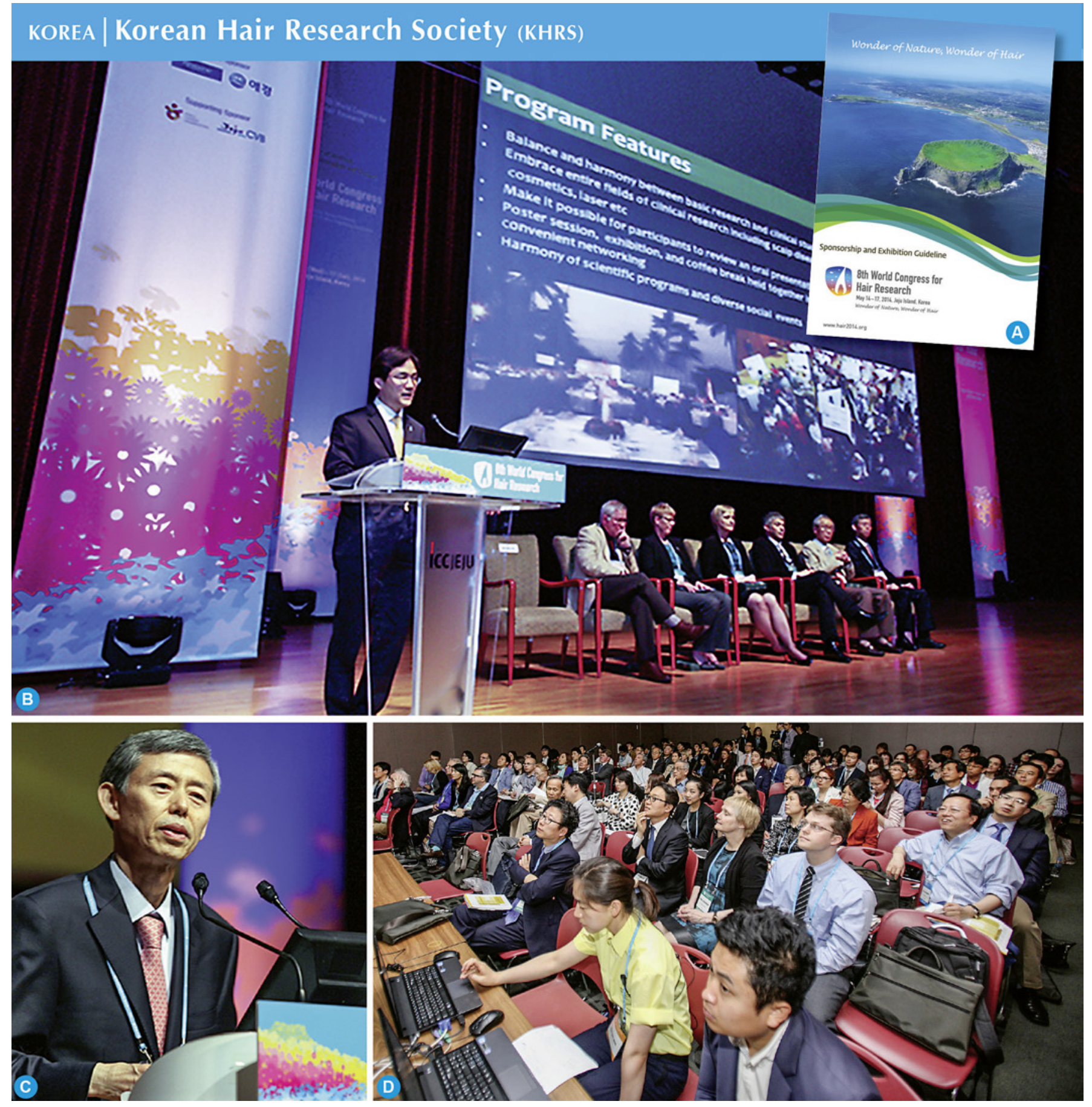

Fig. 20. Korea. A Program cover from WCHR2014 Jeju Island. B WCHR2014 Congress President, Dr. Won-Soo Lee, welcomes delegates with IFHRS representatives on stage. C KHRS President, Dr. Do-Won Kim, provides opening remarks at WCHR2014. D Attendees of WCHR2014. 


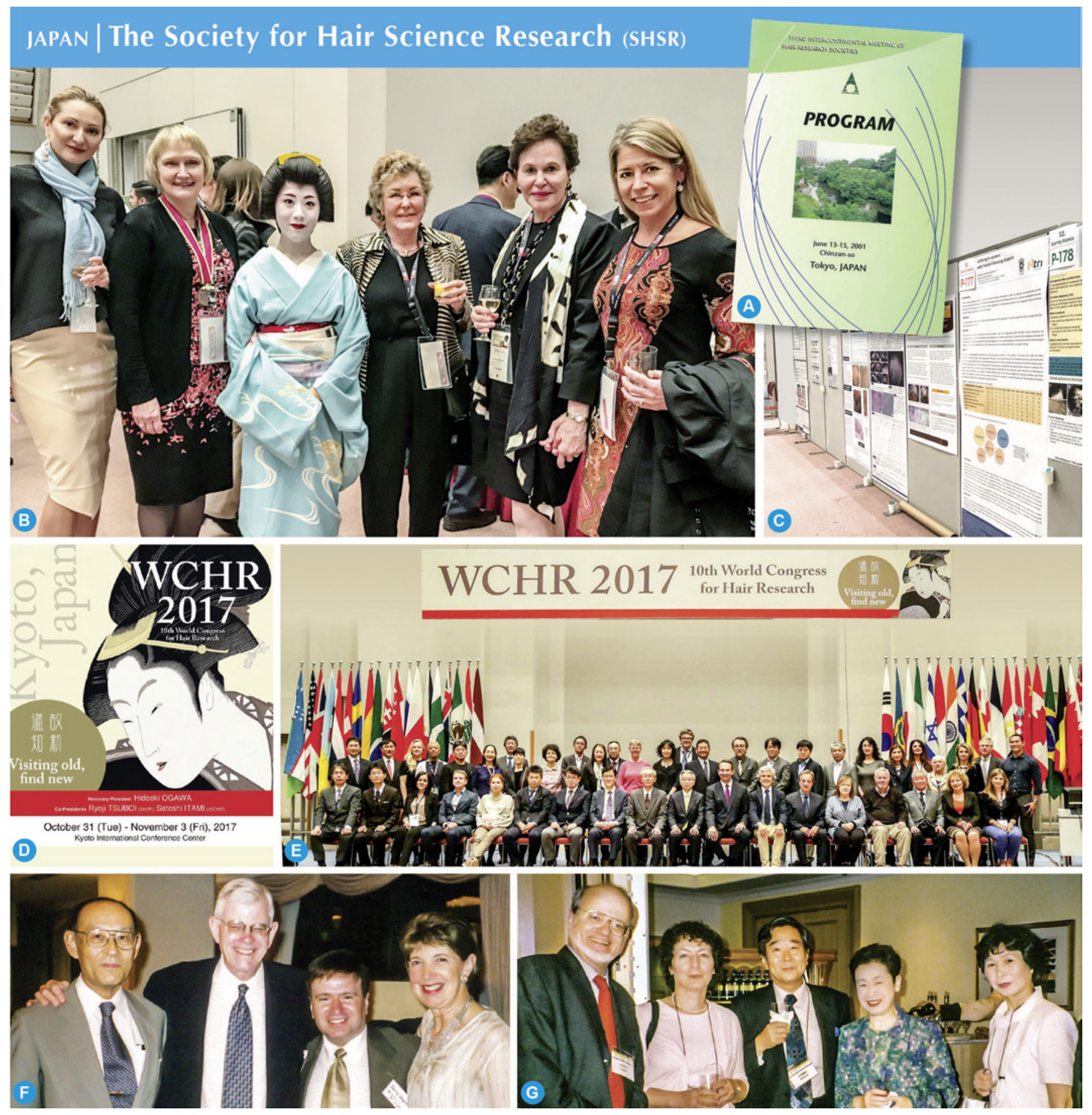

Fig. 21. Japan. A Program cover from Third Intercontinental Meeting of Hair Research Societies (2001), Tokyo. B Drs. Natasha Mesinkovska, Maria Hordinsky, geisha girl, Janet Roberts, Wilma Bergfeld, and Victoria Ceh at WCHR2017 welcome reception. C Scientific poster presentations at WCHR2017. D Program cover from WCHR2017 Kyoto. E Faculty of WCHR2017. F Drs. Susumu Takayasu, David Whiting, Jerry Shapiro, and Vera Price at WCHR2001. G Drs. Rudolf Happle, Valerie Randall, Hideoki Ogawa, Ms. Teruko Ogawa, and Ms. Takayasu at WCHR2001. 


\section{AUSTRALASIAN | Australasian Hair and Wool Research Society (AHWRS)}

INTERNATIONAL | International Federation of Hair Research Societies (IFHRS)
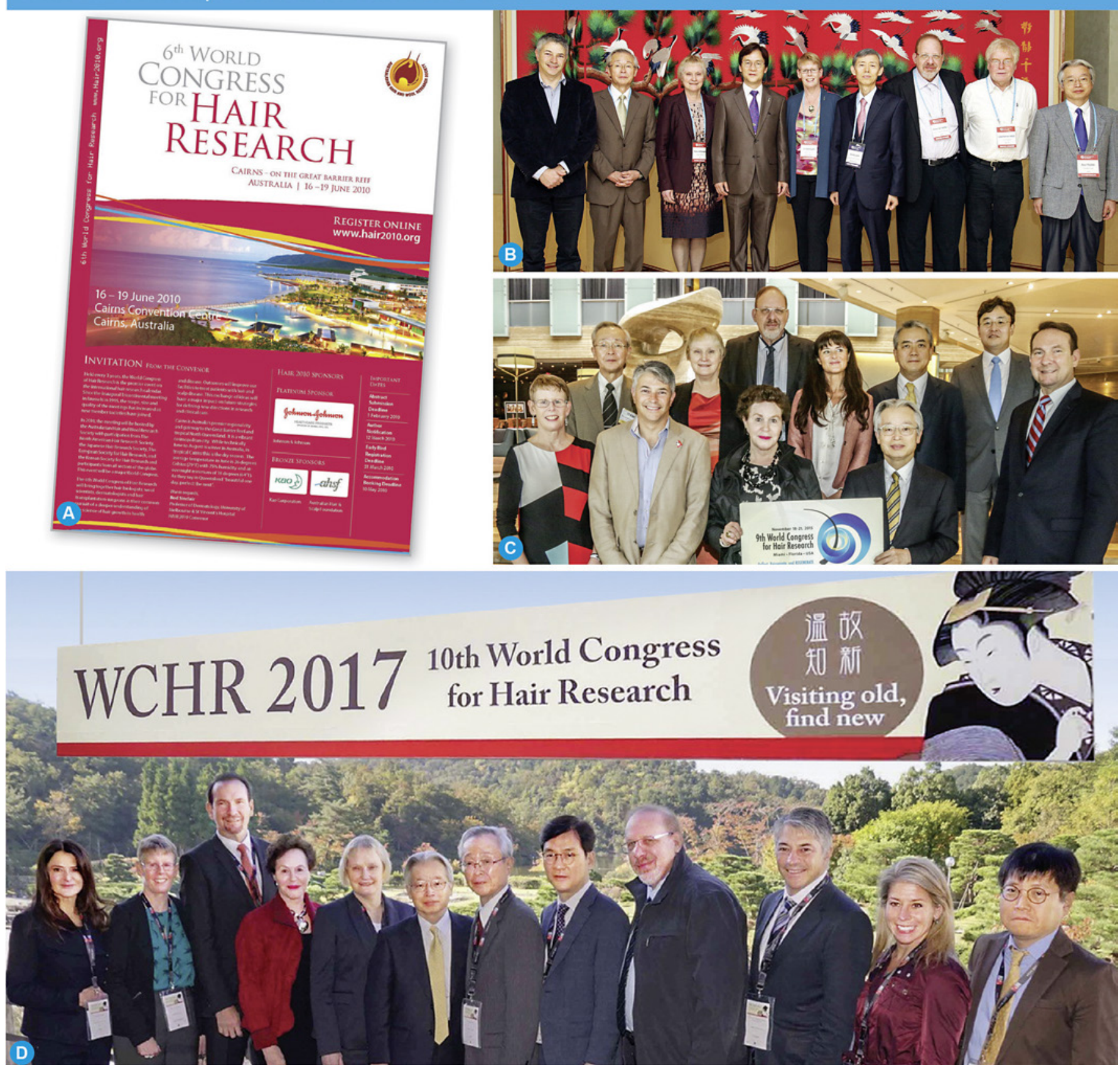

Fig. 22. Australasian and IFHRS. A Program cover from WCHR2010 Cairns. B IFHRS representatives at WCHR2014 - Drs. Rodney Sinclair, Satoshi Itami, Maria Hordinsky, Won-Soo Lee, Gillian Westgate, Do-Won Kim, Abraham Zlotogorski, Les Jones, Ryoji Tsuboi. C IFHRS representatives at WCHR2015 - front row: Drs. Gillian Westgate, Rodney Sinclair, Wilma Bergfeld, Ryoji Tsuboi, and Ken Washenik; back row: Drs. Satoshi Itami, Maria Hordinsky, Abraham Zlotogorski, Bianca Maria Piraccini, Woo Young Sim, and Hoon Kang. D IFHRS representatives at WCHR2017 - Drs. Bianca Maria Piraccini, Gillian Westgate, Ken Washenik, Wilma Bergfeld, Maria Hordinsky, Ryoji Tsuboi, Satoshi Itami, Won-Soo Lee, Abraham Zlotogorski, Rodney Sinclair, Victoria Ceh, and Gwang Seong Choi. 